УДК 368.5

$10.17213 / 2075-2067-2020-6-202-210$

\title{
РЫНОК АГРОСТРАХОВАНИЯ: ВОЗМОЖЕН ЛИ РОСТ?
}

\author{
(C) 2020 г. Е. Г. Мещцанинова, А. И. Чернова
}

\begin{abstract}
Новочеркасский инженерно-мелиоративный институт имени А. К. Кортунова (филиал), Донской государственный аграрный университет, г. Новочеркасск, Россия
\end{abstract}

Целью исследования является изучение предпосылок для роста объемов агрострахования путем анализа недостатков современной системы агрострахования в России, действующей правовой основы и видов современного аграрного страхования.

Методологической основой исследования являются работы российских ученых-экономистов, исследующих приоритетные направления развития системь агрострахования. В настоящее время сектор агрострахования в России представляет собой сформировавшуюся, однако еще недостаточно развитую структуру. В исследовании используются статистический метод и метод сравнительного анализа.

Результаты исследования. Аграрное производство отличается больиим количеством непредсказуемых рисков, вследствие которых отрасль несет колоссальные убытки. Агрострахование является эффективным инструментом возмещения финансовых потерь, но его доступность возможна только при государственной поддержке. Однако, проведенныий анализ развития агрострахования в России показал, что построение эффективной, стабильной системы агрострахования с государственной поддержкой возможно только при учете мнения всех заинтересованных сторон: государства, сельхозпроизводителей и страховщиков.

Перспективу исследования составляет дальнейшее изучение взаимодействия страховых организачий, региональных консультационных центров, сельхозтоваропроизводителей и органов государственной власти для совершенствования системы агрострахования.

Ключевые слова: аграрное страхование; сельскохозяйственные культуры и животные; урожай; риски; субсидии; государственная поддержка.

\section{AGRICULTURAL INSURANCE MARKET: IS GROWTH POSSIBLE?}

\section{(C) 2020 E. G. Meshchaninova, A. I. Chernova}

\section{Novocherkassk Reclamation Engineering Institute named after A. K. Kortunov (branch), Donskoy State Agrarian University, Novocherkassk, Russia}

The purpose of the study is to study the prerequisites for the growth of agricultural insurance by analyzing the shortcomings of the modern agricultural insurance system in Russia, the current legal framework and types of modern agricultural insurance.

The methodological basis of the research is the work of Russian scientists and economists who study the priority directions of development of the agricultural insurance system. Currently, the agricultural insurance sector in Russia is an established, but not yet sufficiently developed structure. The study uses a statistical method and a method of comparative analysis.

Research result. Agricultural production is characterized by a large number of unpredictable risks, due to which the industry suffers huge losses. Agricultural insurance is an effective tool for 
compensation of financial losses, but its availability is possible only with state support. However, the analysis of the development of agricultural insurance in Russia has shown that the construction of an effective, stable system of agricultural insurance with state support is possible only when taking into account the views of all interested parties: the state, agricultural producers and insurers.

The perspective of the research is to further study the interaction of insurance organizations, regional consulting centers, agricultural producers and public authorities to improve the system of agricultural insurance.

Key words: agricultural insurance; crops and animals; crop; risks; subsidies; state support.

Введение. Агропромышленный комплекс - отрасль, подверженная воздействию целого ряда опасных явлений природного характера, приводящих к гибели сельскохозяйственных посевов и животных, поэтому во многих странах мира одним из основных механизмов финансовой защиты сельхозпроизводителя является агрострахование. Агрострахование призвано защитить сельскохозяйственных производителей от убытков, которые они несут в случае возникновения страховых случаев путем предоставления им финансовой помощи от естественных рисков. Основной целью аграрного страхования является улучшение кредитоспособности сельскохозяйственных производителей, а также частичное или полное возмещение потерь их урожая $[6,11]$.

Основываясь на данных Министерства сельского хозяйства Российской Федерации, отметим, что за период с 2012 по 2017 годы ущерб от опасных явлений природного характера достиг 41,21 млрд. руб. В указанный период пострадали более 23,2 тыс. хозяйств, а по договорам страхования сельскохозяйственных рисков выплачено 27,2 млрд. руб. страхового возмещения [4].

«В 2019 году общий ущерб сельхозпроизводителей от природных катаклизмов оценивается в 13 млрд. рублей, погибло 1,9\% от общей площади посевов», - заявил в Совете Федерации директор департамента растениеводства Минсельхоза Роман Некрасов. Также он отметил, что площадь гибели сельхозкультур превысила 1,5 млн. га. Потери аграриев шести регионов были возмещены из резервного фонда правительства, по остальным Минсельхоз по постановлению правительства выплатит заявленный ущерб до конца года. Засухи, выпревание и вымер- зание посевов, пожары и паводок в 2019 году были в 25 регионах, там вводили режим ЧС. От засухи пострадали аграрии Пензенской, Саратовской, Оренбургской, Челябинской и Нижегородской областей, Башкирии, Чувашии и ряда других регионов. Переувлажнение почвы отмечено в Мордовии, Томской, Вологодской и Новгородской областях, выпревание посевов - в Мордовии, Саратовской и Кировской областях [8].

Исходя из вышеизложенного, можно сделать вывод, что серьезные погодные риски во многих регионах страны обуславливают необходимость рассмотрения агрострахования как одного из эффективных механизмов обеспечения финансовой устойчивости сельского хозяйства.

Анализ видов современного российского агрострахования и действующей правовой основы. Современная система агрострахования сформирована на основе концепции страхования сельхозпроизводителей с государственной поддержкой до 2020 года. Основные виды сельскохозяйственного страхования в России представлены на рисунке 1 .

Сельское хозяйство подвержено большому количеству рисков, которые невозможно предвидеть, несмотря на инновации и технические достижения. Основные риски для урожая растительных культур и животноводства, подлежащие аграрному страхованию, представлены на рисунке 2.

По данным опроса сельскохозяйственных производителей, в России зафиксированы недостаточные объемы субсидирования программы страхования. Примером данного факта может служить показатель застрахованного крупного рогатого скота - 16,7\% от всего имеющегося поголовья в стране. При 
этом в системе аграрного страхования США, например, четко определены все риски, а объем выделяемых субсидий в 40 раз больше, чем в России. В Израиле страхование носит обязательный характер, поэтому доля застрахованных производителей составляет $100 \%$, в США застраховано две трети всех засеянных площадей [2]. Уклон российской государственной программы аграрного страхования направлен на растениеводство, и лишь несколько позиций - в животноводстве и аквакультурах.

По результатам исследования Всемирного банка, Россия занимает восьмое место в мировом рейтинге стран по размеру страховых взносов в аграрное страхование.

Анализ процесса формирования российской системы аграрного страхования показал, что она не может эффективно функционировать без государственной поддержки. Правовая основа действующей системы аграрного стра- хования с государственной поддержкой в России базируется на двух федеральных законах:

1) Федеральный закон №264«О развитии сельского хозяйства» [15], действующий с 2007 года. Данный документ устанавливает основы аграрной политики, а также регламентирует условия федерального финансирования программ государственной поддержки;

2) Федеральный закон №260 «О государственной поддержке в сфере сельскохозяйственного страхования и о внесении изменений в Федеральный закон “О развитии сельского хозяйства"», действующий с 2012 года [14]. Указанный специализированный закон регулирует условия субсидируемого аграрного страхования.

С 1 января 2016 года на рынке сельскохозяйственного страхования с государственной поддержкой действует единое общероссийское объединение - Национальный союз

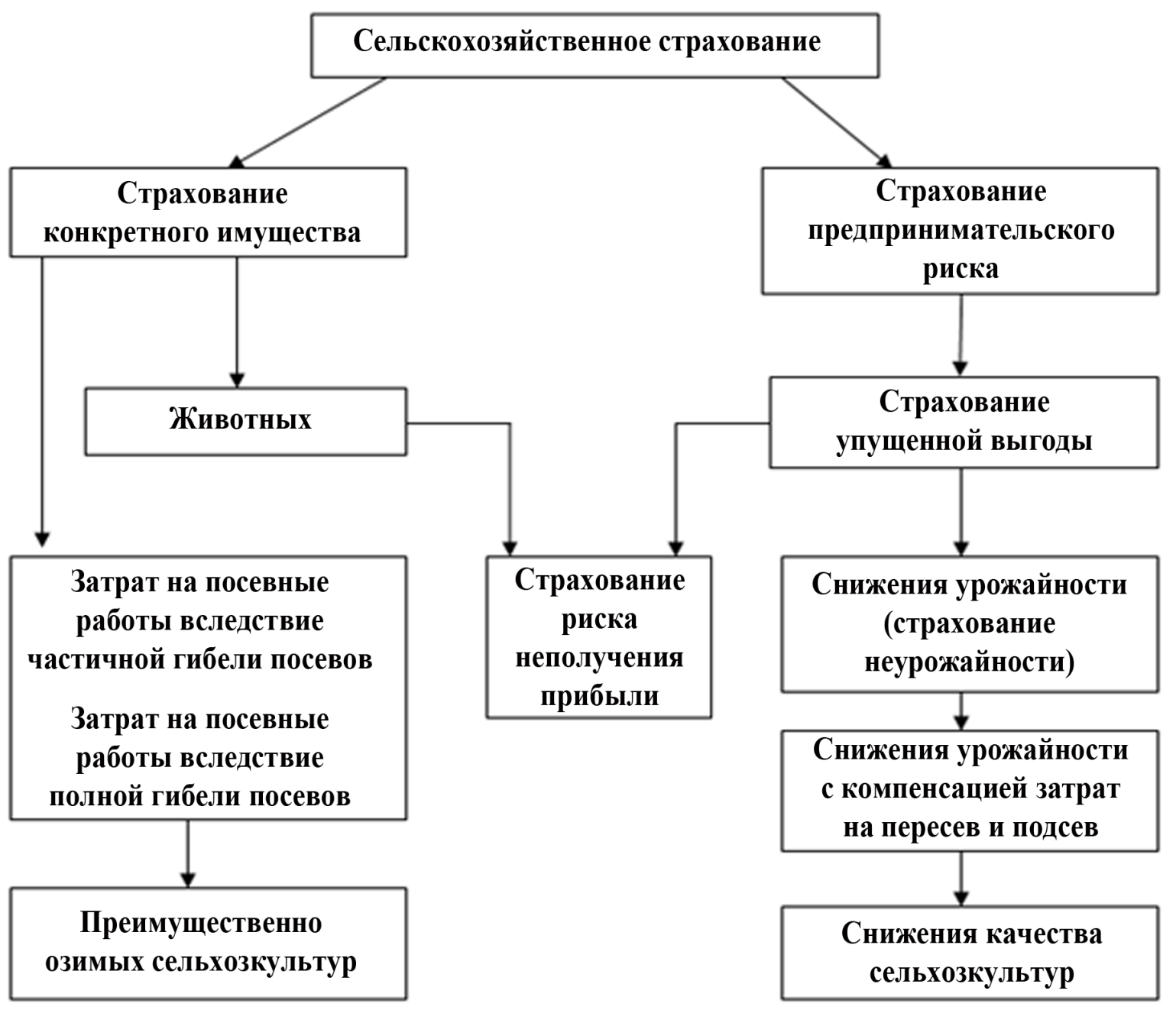

Рис. 1. Основные виды сельскохозяйственного страхования в России [9] 
агростраховщиков, который устанавливает и принимает правила страхования.

В 2018 году в закон №260 были внесены изменения, целью которых стали гибкость и разнообразие условий сельскохозяйственного страхования.

С 1 января 2019 года вступил в силу закон №109 [16], распространивший государственную поддержку на страхование объектов товарной аквакультуры.

С 11 января 2020 года вступил в силу план сельскохозяйственного страхования на 2020 год [10]. Указанный документ утверждается ежегодно и содержит перечень сельскохозяйственных объектов - видов культур, животных и рыбы, риски выращивания которых возможно застраховать в текущем году при поддержке государства. Следует отметить, что в этом году расширены возможности страхования рыбы.

Документом также утверждены для каждого субъекта РФ и для каждой группы сель- скохозяйственных объектов ставки субсидирования, необходимые для расчета размера субсидии, которая будет перечислена из бюджета на оплату страхового полиса при их страховании с господдержкой.

Важно отметить, что система аграрного страхования совершенствуется с каждым годом. Так, с 1 марта 2019 года вступил в силу Федеральный закон №563 [13], направленный на повышение доступности сельскохозяйственного страхования с государственной поддержкой для аграриев, повышение охвата страховой защиты посевных площадей и поголовья сельскохозяйственных животных, придание легитимности использованию космического мониторинга при проведении экспертиз по договорам аграрного страхования с господдержкой.

В соответствии с решением комитета по мониторингу и страховой экспертизе в 2020 году запланирована разработка методик сопровождения и урегулирования убыт-

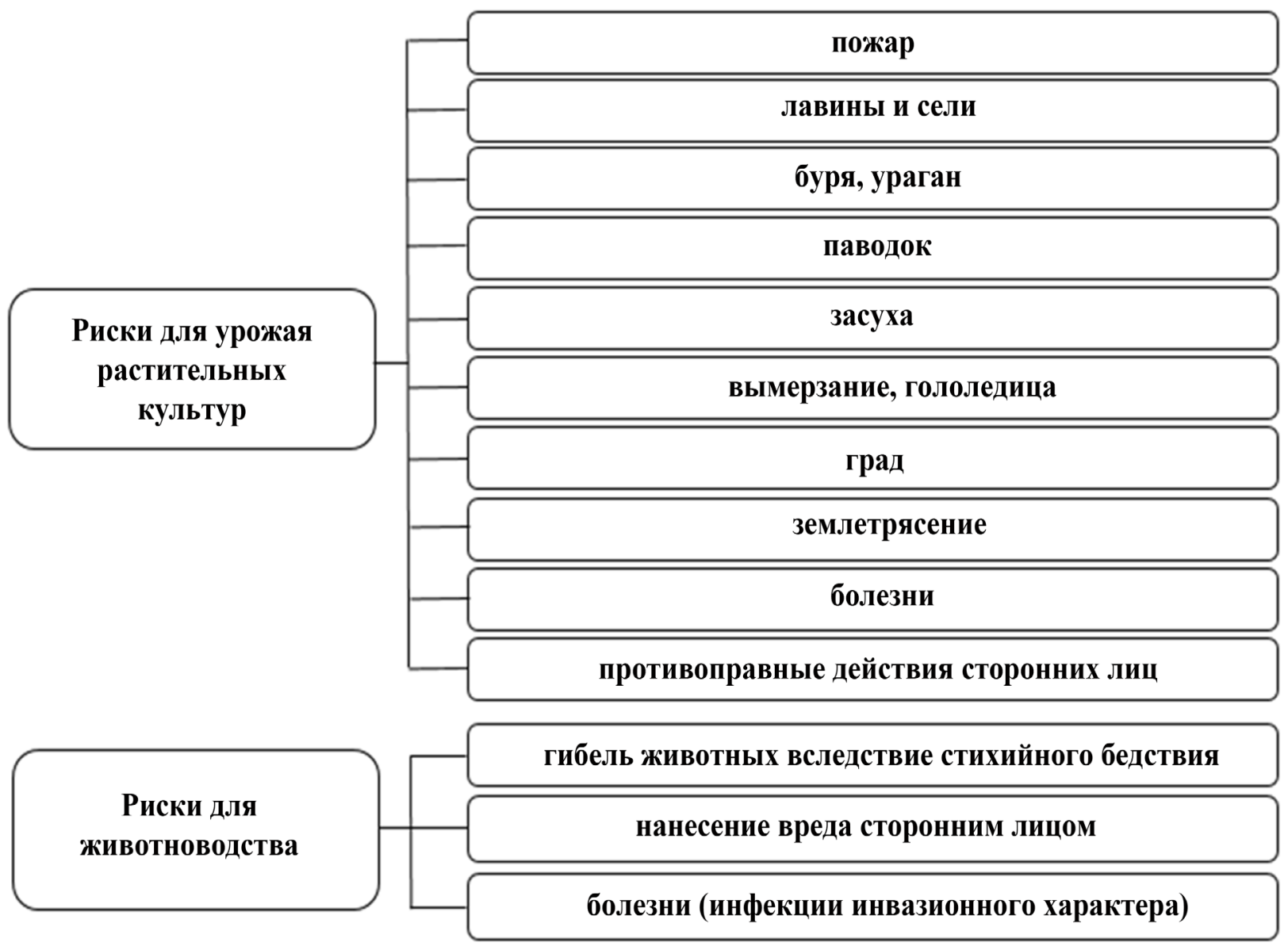

Рис. 2. Основные риски для урожая растительных культур и животноводства, подлежащие аграрному страхованию [17] 
ков с использованием данных космического мониторинга. К сожалению, несмотря на ежегодное совершенствование изучаемой системы, по многим показателям она отстает от зарубежных.

В 2020 году государственная поддержка аграрного страхования в России увеличена с 1,5 млрд. рублей (в 2019 год) до 2,2 млрд. рублей (на 46,6\%), благодаря чему объемы застрахованных посевных площадей и поголовья сельскохозяйственных животных также значительно увеличились по сравнению с аналогичным периодом прошлого года. На июль 2020 года застраховано 917,8 тыс. га посевной (посадочной) площади, что в 2,7 раза больше, чем за аналогичный период 2019 года. Среди регионов страны наибольший размер застрахованной посевной площади — в Воронежской области, а лидером по застрахованному поголовью сельскохозяйственных животных является Белгородская область (таблица 1).

По мнению Корнея Биждова - президента НСА России, «даже при возможном приближении охвата посевов страхованием в текущем году к 10\% от посевной площади еще не будет решена главная задача - перенос на систему агрострахования основной части нагрузки по компенсации ущерба аграриям при ЧС, как это происходит в странах с развитым агрострахованием» [5].

Заключение. Страхование — важная составляющая часть рыночной экономики Рос- сийской Федерации, а страхование в сельскохозяйственном секторе - не только эффективный инструмент управления рисками, но один из самых сложных видов страхования с точки зрения его организации и проведения [7].

Сейчас в России действует мультирисковая система агрострахования. Вне зависимости от того, когда случилось страховое событие (погодные катаклизмы, болезни и т.п.), возмещение по нему растениеводам выплачивается по завершении сельхозсезона в том случае, если по итогам уборочной отмечается снижение урожайности.

Также в правовой базе аграрного страхования не регламентированы аспекты защиты интересов и прав сельскохозяйственных производителей в их отношениях со страховыми компаниями, что является одной из причин низкого охвата страхованием как площадей сельскохозяйственных культур, так и поголовья сельскохозяйственных животных. Это возможно решить только при условии диверсификации программ страхования - для разных сегментов агробизнеса и региональных условий. Специфика сельскохозяйственного страхования такова, что к повышению страхового риска приводит большое количество случайностей, которые никак не зависят от человеческого фактора. Тарифные ставки в этом сегменте рынка страхования достаточно высокие, а перечень правил надежности агростраховщиков, содержащихся в нормативно-правовых документах, весьма небольшой [1]. Некоторые организации не имеют

Регионы - лидеры по агрострахованию в 2020 году в России [3]

Таблица 1

\begin{tabular}{|c|l|c|}
\hline Место в рейтинге & \multicolumn{1}{|c|}{ Регион } & Показатель \\
\hline \multicolumn{3}{|c|}{ Застрахованная посевная площадь, тыс. га } \\
\hline 1 & Воронежская область & 196 \\
\hline 2 & Ставропольский край & 159,6 \\
\hline 3 & Республика Мордовия & 120 \\
\hline 4 & Тамбовская область & 110,2 \\
\hline Застрахованное поголовье сельскохозяйственных животных, тыс. усл. гол. \\
\hline 1 & Белгородская область & 604,9 \\
\hline 2 & Пензенская область & 307 \\
\hline 3 & Брянская область & 242,2 \\
\hline 4 & Курская область & 179,2 \\
\hline
\end{tabular}


официальных рейтингов надежности, на которые необходимо обращать внимание при выборе компании-агростраховщика. Представленные проблемы могут стать фактором банкротств, а также внушительных объемов невыплат страхового возмещения в периоды серьезных природных катаклизмов и утрат урожая [12].

Таким образом, в настоящее время российская система аграрного страхования имеет ряд проблем, которые не позволяют ей эффективно развиваться, тем самым увеличивая риски продовольственной и экономической безопасности регионов и страны в целом.

\section{Литература}

1. Бадртдинова И.И. Агрострахование с государственной поддержкой в Российской Федерации: состояние, проблемы, перспективы развития // Продовольственная политика и безопасность. — 2016. - Т. 3. — №1. C. $41-60$.

2. Богачев А.И. Развитие российского рынка агрострахования животных в условиях действия единой субсидии // Вестник сельского развития и социальной политики. 2018. - №2 (18). - С. 34-36.

3. В России продолжается рост темпов агрострахования [Электронный ресурс]. Режим доступа: https://www.agroxxi.ru/ rossiiskie-agronovosti/v-rossii-prodolzhaetsjarost-tempov-agrostrahovanija.html.

4. Виноходова И.Г. Рынок агрострахования РФ на современном этапе и приоритетные направления его развития [Электронный ресурс] // Известия Великолукской государственной сельскохозяйственной академии. - 2018. - №4. - Режим доступа: https://cyberleninka.ru/article/n/rynokagrostrahovaniya-rf-na-sovremennom-etape-iprioritetnye-napravleniya-ego-razvitiya.

5. Карабут T. Аграриизастраховаливтрое больше посевов [Электронный ресурс]// Российская газета. - Федеральный выпуск №146 (8200). - Режим доступа: https:// rg.ru/2020/07/06/reg-cfo/rossijskie-agrariizastrahovali-bolee-13-mln-ga-ploshchadej.html.

6. Мещзанинова Е.Г. Агрострахование в России: проблемы и инструменты // В сборнике: Актуальные проблемы и перспективы развития экономики. Труды XVIII Bсерос- сийской с международным участием научнопрактической конференции / Под редакцией Н.В. Апатовой. - 2019. - С. 179-180.

7. Мешанинова Е.Г., Ткачева О.А. Оценка эколого-экономического состояния землепользований Ростовской области // Землеустройство, кадастр и мониторинг земель. 2013. - №2 (98). - С. 63-69.

8. Минсельхоз оценил в 13 млрд. рублей ущерб сельхозпроизводителей от природных катаклизмов [Электронный ресурс]. — Режим доступа: https://www.interfax.ru/russia/686005.

9. Миронова Н. А. Агрострахование в Российской Федерации: проблемы, особенности, перспективы // Московский экономический журнал. — 2020. — №5. - С. 489-4962.

10. Приказ Министерства сельского хозяйства РФ от 2 декабря 2019 г. №667 «Об утверждении Плана сельскохозяйственного страхования на 2020 год» [Электронный ресурc]. - Режим доступа: https://www.garant.ru.

11. Соломкина Л.Г. Землепользование и аграрные преобразования // Экономика сельского хозяйства России. - 2001. №3. - С. 30.

12. Углицких О.Н., Клишина Ю.Е. Проблемы современной системы сельскохозяйственного страхования и пути их решения // Kant. - 2017. - №2 (23). - C. 231-235.

13. Федеральный закон «О внесении изменений в Федеральный закон "О государственной поддержке в сфере сельскохозяйственного страхования" и о внесении изменений в Федеральный закон "О развитии сельского хозяйства”» от 27.12.2018 г. №563-Ф3 [Электронный ресурс]. - Режим доступа: http://www.consultant.ru.

14. Федеральный закон «О государственной поддержке в сфере сельскохозяйственного страхования и о внесении изменений в Федеральный закон "О развитии сельского хозяйства”» от 25.07.2011 г. №260-Ф3 [Электронный ресурс]. - Режим доступа: http:// www.consultant.ru.

15. Федеральный закон «О развитии сельского хозяйства» от 29.12.2006 г. №264Ф3 [Электронный ресурс]. — Режим доступа: http://www.consultant.ru.

16. Федеральный закон «Об аквакультуре (рыбоводстве) и о внесении изменений в отдельные законодательные акты Российской Федерации» от 02.07.2013 г. №148-Ф3 [Элек- 
тронный ресурс]. - Режим доступа: http:// www.consultant.ru.

17. Эльдиева Т. М. Современное состояние системы страхования в сельском хозяйстве России // Международный сельскохозяйственный журнал. - 2018. — №1 (361). - С. 20-22.

\section{References}

1. Badrtdinova I.I. Agrostrahovanie s gosudarstvennoj podderzhkoj v Rossijskoj Federacii: sostojanie, problemy, perspektivy razvitija [Agricultural Insurance with state support in the Russian Federation: state, problems, development prospects] // Prodovol'stvennaja politika i bezopasnost' [Food policy and security]. 2016. - Vol. 3. - №1. - Pp. 41-60.

2. Bogachev A. I. Razvitie rossijskogo rynka agrostrahovanija zhivotnyh v uslovijah dejstvija edinoj subsidii [Development of the Russian market of agricultural insurance of animals in the conditions of the unified subsidy] // Vestnik sel'skogo razvitija i social'noj politiki [Bulletin of rural development and social policy]. 2018. — №2 (18). — Pp. 34-36.

3. V Rossii prodolzhaetsja rost tempov agrostrahovanija [In Russia the growth rate of agricultural insurance continues] [Jelektronnyj resurs]. — URL: https://www.agroxxi.ru/rossiiskie-agronovosti/v-rossii-prodolzhaetsja-rosttempov-agrostrahovanija.html.

4. Vinohodova I. G. Rynok agrostrahovanija RF na sovremennom jetape i prioritetnye napravlenija ego razvitija [Agricultural insurance market of the Russian Federation at the present stage and priority directions of its development] [Jelektronnyj resurs] // Izvestija Velikolukskoj gosudarstvennoj sel'skohozjajstvennoj akademii [Proceedings of the Velikiye Luki state agricultural Academy]. — 2018. — №4. — URL: https://cyberleninka.ru/article/n/rynok-agrostrahovaniya-rf-na-sovremennom-etape-i-prioritetnye-napravleniya-ego-razvitiya.

5. Karabut T. Agrarii zastrahovali vtroe bol'she posevov [Agrarians insured three times more crops] [Jelektronnyj resurs] // Rossijskaja gazeta. - Federal issue №146 (8200). — URL: https://rg.ru/2020/07/06/reg-cfo/rossijskie-agrariizastrahovali-bolee-13-mln-ga-ploshchadej.html.

6. Meshhaninova E.G. Agrostrahovanie v Rossii: problemy i instrumenty [Agricultural Insurance in Russia: problems and tools] // V sbornike: Aktual'nye problemy i perspektivy razvitija jekonomiki. Trudy XVIII Vserossijskoj $\mathrm{s}$ mezhdunarodnym uchastiem nauchno-prakticheskoj konferencii [In the collection: Current problems and prospects of economic development. Proceedings of the XVIII all-Russian scientific and practical conference with international participation] / In N. V. Apatova (eds.). 2019. - Pp. 179-180.

7. Meshhaninova E. G., Tkacheva O.A. Ocenka jekologo-jekonomicheskogo sostojanija zemlepol'zovanij Rostovskoj oblasti [Assessment of the ecological and economic state of land use in the Rostov region] // Zemleustrojstvo, kadastr i monitoring zemel' [Land management, cadastre and land monitoring]. — 2013. - №2 (98). Pp. 63-69.

8. Minsel'hoz ocenil v 13 mlrd. rublej ushherb sel'hozproizvoditelej ot prirodnyh kataklizmov [The Ministry of agriculture estimated the damage to agricultural producers from natural disasters at 13 billion rubles] [Jelektronnyj resurs]. — URL: https://www.interfax.ru/russia/ 686005 .

9. Mironova N.A. Agrostrahovanie v Rossijskoj Federacii: problemy, osobennosti, perspektivy [Agroinsurance in the Russian Federation: problems, features, prospects] // Moskovskij jekonomicheskij zhurnal [Moscow economic journal]. — 2020. — №5. — Pp. 489-4962.

10. Prikaz Ministerstva sel'skogo hozjajstva RF ot 2 dekabrja 2019 g. №667 «Ob utverzhdenii Plana sel'skohozjajstvennogo strahovanija na 2020 god» [Order of the Ministry of agriculture of the Russian Federation №667 dated December 2, 2019 «On approval of the agricultural insurance Plan for 2020»] [Jelektronnyj resurs]. URL: https://www.garant.ru.

11. Solomkina L.G. Zemlepol'zovanie i agrarnye preobrazovanija [Land use and agrarian transformations] // Jekonomika sel'skogo hozjajstva Rossii [Economics of agriculture of Russia]. — 2001. — №3. - P. 30.

12. Uglickih O. N., Klishina Ju. E. Problemy sovremennoj sistemy sel'skohozjajstvennogo strahovanija i puti ih reshenija [Problems of the modern agricultural insurance system and ways to solve them] // Kant. — 2017. - №2 (23). Pp. 231-235.

13. Federal'nyj zakon «O vnesenii izmenenij v Federal'nyj zakon "O gosudarstvennoj podderzhke $\mathrm{v}$ sfere sel'skohozjajstvennogo stra- 
hovanija" i o vnesenii izmenenij v Federal'nyj zakon "O razvitii sel'skogo hozjajstva"» ot 27.12.2018 g. №563-FZ [Federal law «On amendments to the Federal law "On state support in the field of agricultural insurance" and on amendments to the Federal law "On agricultural development”» dated 27.12.2018 №563-FZ] [Jelektronnyj resurs]. — URL: http://www.consultant.ru.

14. Federal'nyj zakon «O gosudarstvennoj podderzhke v sfere sel'skohozjajstvennogo strahovanija i o vnesenii izmenenij v Federal'nyj zakon "O razvitii sel'skogo hozjajstva"» ot 25.07.2011 g. №260-FZ [Federal law «On state support in the field of agricultural insurance and on amendments to the Federal law "On agricultural development"》 from 25.07.2011 №260FZ] [Jelektronnyj resurs]. — URL: http://www. consultant.ru.
15. Federal'nyj zakon «O razvitii sel'skogo hozjajstva» ot 29.12.2006 g. №264-FZ [Federal law «On the development of agriculture» of 29.12.2006 №264-FZ] [Jelektronnyj resurs]. URL: http://www.consultant.ru.

16. Federal'nyj zakon «Ob akvakul'ture (rybovodstve) i o vnesenii izmenenij v otdel'nye zakonodatel'nye akty Rossijskoj Federacii»» ot 02.07.2013 g. №148-FZ [Federal law «On aquaculture (fish farming) and on amendments to certain legislative acts of the Russian Federation» of 02.07.2013№148-FZ] [Jelektronnyj resurs]. URL: http://www.consultant.ru.

17. Jel'dieva T.M. Sovremennoe sostojanie sistemy strahovanija v sel'skom hozjajstve Rossii [Current state of the insurance system in agriculture inRussia]//Mezhdunarodnyj sel'skohozjajstvennyj zhurnal [International agricultural journal]. 2018. — №1 (361). — Pp. 20-22.

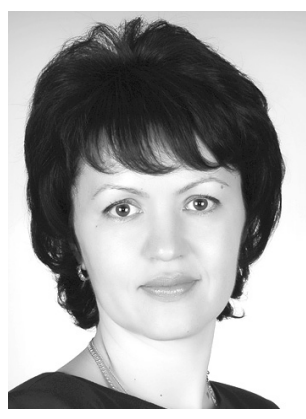

\begin{abstract}
Мещанинова Елена Германовна - кандидат экономических наук, доцент кафедры «Кадастр и мониторинг земель» Новочеркасского инженерно-мелиоративного института им. А.К. Кортунова. Является автором работ по эколого-экономической оценке природопользования, рациональному аграрному природопользованию.
\end{abstract}

Meshchaninova Elena Germanovna - Candidate of Economic Sciences, Associate Professor of the Department of Cadastre and Land Monitoring, Novocherkassk Reclamation Engineering Institute named after A.K. Kortunov (branch), Donskoy State Agrarian University. He is the author of works on environmental and economic assessment of nature management, rational agricultural nature management.

346400, г. Новочеркасск, ул. Пушкинская, 111

111 Pushkinskaya st., 346400, Novocherkassk, Russia

E-mail: forpost-MEG@yandex.ru 


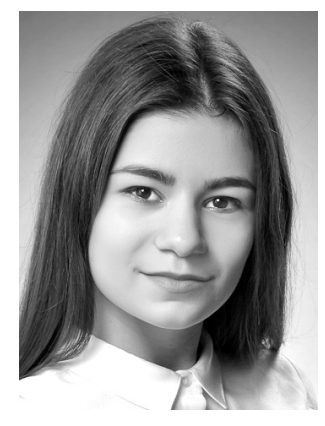

Чернова Анна Ильинична - студент землеустроительного факультета Новочеркасского инженерно-мелиоративного института им. А.К. Кортунова.

Chernova Anna Ilinichna - a student of the Land Management faculty, Novocherkassk Reclamation Engineering Institute named after A. K. Kortunov (branch), Donskoy State Agrarian University.

346400 , г. Новочеркасск, ул. Пушкинская, 111

111 Pushkinskaya st., 346400, Novocherkassk, Russia

E-mail: achernova1999@mail.ru 